\title{
Attenuation of Androgen Receptor-Dependent Transcription by the Serine/Threonine Kinase Pim-1
}

\author{
James Thompson, Katriina J. Peltola, Päivi J. Koskinen, Olli A. Jänne, and \\ Jorma J. Palvimo \\ Biomedicum Helsinki, Institute of Biomedicine/Physiology (JT, OAJ, JJP), Department of Clinical Chemistry (OAJ), \\ University of Helsinki and Helsinki University Central Hospital, Helsinki, and Turku Centre for Biotechnology (KJP, \\ PJK), University of Turku/Åbo Akademi, Turku, Finland
}

\begin{abstract}
SUMMARY: Androgens play a key role in the regulation of the normal prostate as well as in the promotion and progression of prostate cancer. Recently, an oncogenic serine/threonine kinase, Pim-1, was reported to be overexpressed in prostate cancer. To elucidate whether Pim-1 is capable of modulating androgen signaling, we studied the effects of Pim-1 on androgen receptor (AR)-dependent transcription. Under transient transfection conditions, Pim-1 attenuated transcriptional activity of AR in a dose-dependent fashion in PC-3, HeLa, and COS-1 cells, whereas a kinase-negative mutant of Pim-1, Pim-1(K67M), showed no repressive activity. In contrast, ectopic expression of Pim-1 did not influence the activity of endogenous AR in LNCaP cells. This was, however, not a result of the T877A mutation present in AR of LNCaP cells, because that AR mutant was repressed by Pim-1 as efficiently as wild-type AR when expressed in PC-3 prostate cancer cells. Pim-1 inhibited AR mutants devoid of the ligand-binding domain or the core amino-terminal transactivation function but failed to influence the DNA binding of AR. Because we found no evidence for phosphorylation of AR by Pim-1 or for direct interaction between these proteins, Pim-1 is likely to influence AR activity via an indirect mechanism, possibly involving phosphorylation of a coregulator and/or a component of the transcription machinery. Overexpression of Pim-1 may thus attenuate androgen response during progression of prostate cancer in a cell context-dependent fashion. (Lab Invest 2003, 83:1301-1309).
\end{abstract}

\begin{abstract}
$A^{\text {ndor }}$ ndrogen receptor (AR) mediates the effects of the two male sex steroids, testosterone $(\mathrm{T})$ and $5 \alpha$ dihydrotestosterone, that are critical in the development and maintenance of the male sexual characteristics. Defective AR function and signaling cause a wide spectrum of androgen insensitivity disorders and are involved in the pathogenesis of prostate cancer (CaP) (Abate-Shen and Shen, 2000), which is the most common malignancy among men in Western societies. AR is a member of the steroid receptor family, a subgroup of the nuclear receptor superfamily. Like all nuclear receptors, the AR protein has a conserved modular structure comprising a nonconserved aminoterminal domain (NTD), a highly conserved DNAbinding domain, and a ligand-binding domain (LBD). Within the AR NTD resides the hormone-independent transcription activation function 1 (AF1) (Beato et al, 1995; Gelmann, 2002; Moras and Gronemeyer, 1998; Palvimo et al, 1993). The AF1 in conjunction with the
\end{abstract}

DOI: 10.1097/01.LAB.0000087585.03162.A3

Received June 13, 2003.

This work was supported by grants from the Medical Research Council (Academy of Finland), the Finnish Foundation for Cancer Research, the Sigrid Jusélius Foundation, Biocentrum Helsinki, Helsinki University Central Hospital, Helsinki Graduate School in Biotechnology and Molecular Biology, and Turku Graduate School of Biomedical Sciences.

Address reprint requests to: Dr. J. J. Palvimo, Biomedicum Helsinki, Institute of Biomedicine/Physiology, P.O. Box 63, University of Helsinki, FIN-00014, Helsinki, Finland. E-mail: Jorma.Palvimo@helsinki.fi conserved NTD FXXLF and WXXLF motifs (He et al, 2000) form, in part, the interaction interface of the NTD with the hormone-dependent activation function 2 (AF2) located in the carboxyl-terminal LBD (Moilanen et al, 1997). Unlike many other steroid receptors, the AF2 of AR is transcriptionally weak (Ikonen et al, 1997; Moilanen et al, 1997). However, the ligand-dependent amino- and carboxyl-terminal interaction is needed for optimal AR function. Upon binding the androgens $T$ or $5 \alpha$-dihydrotestosterone, AR acquires a new conformational state and translocates to the nucleus where it interacts with specific DNA elements (androgen response elements; AREs), coregulators (coactivators and corepressors), and basal transcription machinery (Gelmann, 2002; Quigley et al, 1995).

Disturbances in AR functionality owing to receptor mutations or altered coregulator interactions seem to be linked to the pathogenesis of hormone-dependent and hormone-independent $\mathrm{CaP}$ (Abate-Shen and Shen, 2000; Arnold and Isaacs, 2002; Craft et al, 1999). Gene expression profiling with microarray techniques recently indicated that Pim-1, a 33-kDa serine/ threonine kinase, is overexpressed in half of CaPs, whereas very low levels of expression were seen in most benign prostatic samples (Dhanasekaran et al, 2001). The pim-1 gene was originally identified as a locus frequently activated by proviral insertion of the Moloney murine leukemia virus (Cuypers et al, 1984). Since then pim-1 has been implicated in cytokinedependent signal transduction of hematopoietic cells 
and in development of lymphoid and myeloid malignancies (Amson et al, 1989; Buckley et al, 1995; Dautry et al, 1988; Domen et al, 1993; Lilly et al, 1992). Studies with transgenic mice have revealed that pim-1 can efficiently cooperate with myc family oncogenes in production of lymphomas (Möröy et al, 1991; van Lohuizen et al, 1989). Similar synergism may also play a role in such CaP cells, where expression of both pim-1 and c-myc genes are simultaneously up-regulated (Dhanasekaran et al, 2001).

Normally, pim-1 is highly expressed in hematopoietic tissues and testes (Amson et al, 1989; Sorrentino et al, 1988), but during embryogenesis it can be detected also outside of the immune system in several types of epithelia as well as in the central nervous system (Eichmann et al, 2000). Although the precise functions of Pim-1 have remained largely unknown, evidence is accumulating that Pim-1 can stimulate activities of several transcription factors, such as c-Myb (Leverson et al, 1998) and NFATc1 (Rainio et al, 2002), and protect hematopoietic cells from certain types of apoptosis (Lilly et al, 1999; Möröy et al, 1993). In addition, $\mathrm{Pim}-1$ has been reported to phosphorylate proteins such as Cdc25A phosphatase, p21 cell cycle inhibitor, and the nuclear mitotic apparatus protein (Bhattacharya et al, 2002; Mochizuki et al, 1999; Wang et al, 2002), suggesting that Pim-1 may also play a role in progression through the cell cycle. In this work, we have examined whether ectopic expression of Pim-1 affects AR-dependent transcription in CaP cells.

\section{Results}

\section{Regulation of AR-Dependent Transcription by Pim-1}

To study whether ectopic expression of Pim-1 influences the activity of $A R$, we cotransfected human PC-3 cells, a cancer cell line devoid of endogenous $A R$, with expression vectors encoding human $A R$ and wild-type Pim-1 or a kinase-deficient Pim-1(K67M) mutant together with an AR-responsive probasin promoter-driven luciferase (LUC) reporter, pPB(-285/ +32)-LUC. Increasing amounts of wild-type Pim-1 brought about a marked and dose-dependent decrease in AR-dependent transcription, whereas the kinase-deficient Pim-1(K67M) mutant enhanced slightly, but reproducibly, AR-mediated transcription (Fig. 1A). Similar results were obtained with other $A R$-responsive reporters, such as $\mathrm{pARE}_{2}$ tk-LUC and pARE $_{4}$ tk-LUC (Figs. 3 and 5). In addition, the function of an AR expression vector driven by the CMV promoter (pCMV-hAR) instead of the SV40 promoter (pSG5-hAR; Fig. 1A) was repressed by Pim-1 in a similar fashion (data not shown), indicating that transrepression was not a result of the SV40-driven expression vector. Moreover, the expression of an internal control gene, CMV promoter-driven $\beta$-galactosidase $(\operatorname{pCMV} \beta)$, was not influenced by Pim-1, implying that the repressive effects of Pim-1 on AR-dependent transcription were not caused by general transcriptional squelching. Neither were they a result of reduced AR protein levels, because ectopic expression of both Pim-1 and Pim-1(K67M) only slightly decreased the amount of immunoreactive AR protein in PC-3 cells (Fig. 1B, upper left panel). An immunoblot analysis of Pim-1 and Pim-1(K67M) of the same samples revealed that Pim-1 was slightly less expressed than Pim-1(K67M) (Fig. 1B, lower left panel). Pim-1 inhibited AR-dependent transcription also in COS-1 and HeLa cells (Fig. 1C). In contrast, Pim-1 had no effect on transcriptional activity of endogenous AR in LNCaP cells (Fig. 1D), whereas Pim-1(K67M) slightly attenuated ARdependent transcription. To verify that the lack of repression was not a result of the mutated AR expressed in LNCaP cells (Veldscholte et al, 1990), the T877A mutation was recreated into the $A R$ expression plasmid (pSG5-hART877A) and transfected together with pPB $(-285 /+32)$-LUC and increasing amounts of Pim-1 into PC-3 and COS-1 cells. Pim-1 repressed the transcriptional activity of hART877A as efficiently as that of wild-type AR in both PC-3 cells and COS- 1 cells (Fig. 1E and not shown), indicating that the ability of Pim-1 to modulate AR activity is dependent on the cellular context. We compared levels of endogenous Pim-1 protein in PC-3, LNCaP, and COS- 1 cells by immunoblotting whole cell extracts using an antibody specific for Pim-1. Compared with PC-3 cells ectopically expressing Pim-1, the endogenous level of Pim-1 protein was much lower in both $\mathrm{PC}-3$ and COS-1 cells and barely detectable in LNCaP cells (Fig. 1B, right panel).

\section{Ability of Pim-1 to Phosphorylate AR and the Influence of the AR Mutations S213A and S791A}

The suggested consensus sequence for Pim-1 target sites, $(\mathrm{R} / \mathrm{K})_{3} \mathrm{XS} / \mathrm{T}$ (Friedmann et al, 1992), is similar to that of Akt/protein kinase B (Akt/PKB; Alessi et al, 1996). Interestingly, Akt/PKB has recently been reported to phosphorylate AR at S213 and S791 and thereby down-regulate the function of the receptor (Lin et al, 2001). To examine whether Pim-1 repressed AR activity by direct phosphorylation, we expressed FLAG-tagged AR in COS-1 cells, immunopurified it with an anti-FLAG antibody, and subjected it to in vitro phosphorylation assays with either wild-type Pim-1 or the $\mathrm{K} 67 \mathrm{M}$ mutant that were expressed as glutathioneS-transferase (GST) fusions and purified from Escherichia coli. As shown in Figure 2A, wild-type Pim-1 efficiently autophosphorylated itself, but no ARspecific phosphorylation products could be detected, indicating that $A R$ is not a direct substrate for Pim-1.

Despite the negative results of the in vitro phosphorylation of AR by Pim-1, we examined nevertheless whether sites S213 and S791 mediate transcriptional repression by Pim-1. We created an AR double mutant by substituting both $\mathrm{S} 213$ and $\mathrm{S} 791$ to alanine and investigated transcriptional activity of the mutant with increasing amounts of coexpressed Pim-1 in PC-3 cells. As shown in Figure 2B, the activity of AR mutant S213A/S791A was slightly higher than that of the wild-type $A R$, but its sensitivity to Pim-1 did not differ from that of wild-type receptor (Fig. 2B). Moreover, the expression level of the mutant protein was equal to that of wild-type AR (Fig. 2C). Comparable results 
A

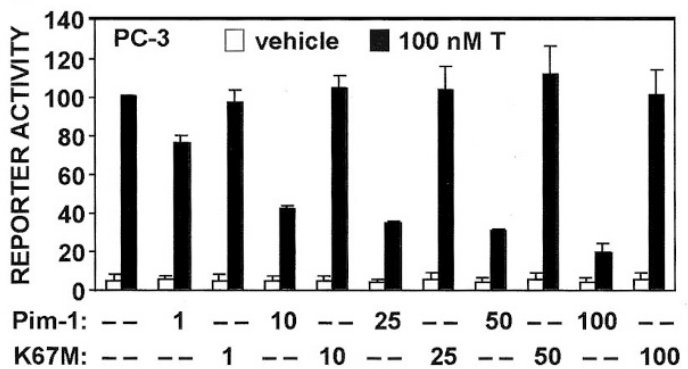

B $\mathrm{kDa}$
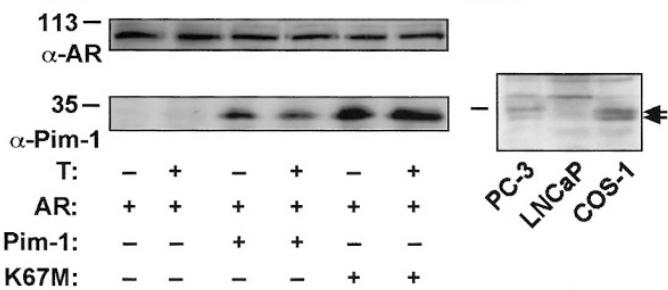

C
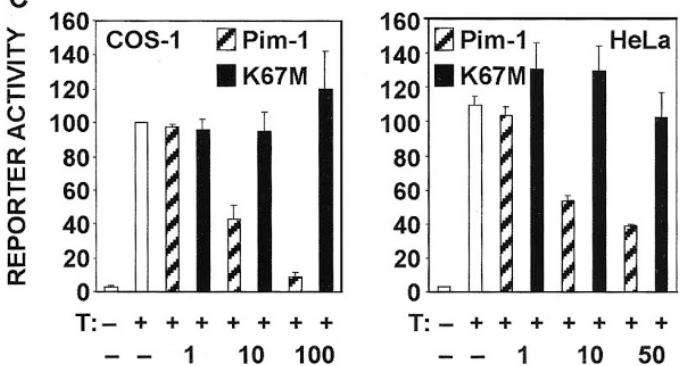

D

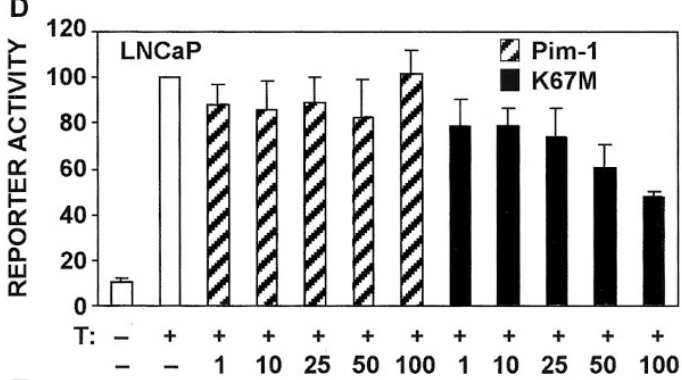

E

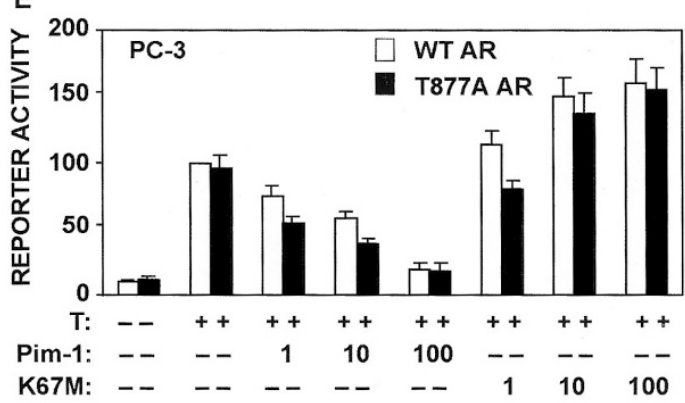

Figure 1.

Effect of overexpressed Pim-1 on androgen receptor (AR)-dependent transcription. A, PC-3 cells were transfected with the expression vectors encoding human AR (pSG5-hAR) $(20 \mathrm{ng})$ along with pPB(-285/+32)-LUC (200 ng), CMV promoterdriven $\beta$-galactosidase $(\mathrm{pCMV} \beta)(50 \mathrm{ng})$, and indicated amounts $(\mathrm{ng})$ of pcDNA3Pim-1 or pcDNA3-Pim-1(K67M). The total amount of DNA per well was kept constant by adding empty pcDNA3 when appropriate. Twenty-four hours after transfection, the cells received fresh medium containing either $100 \mathrm{~nm}$ testosterone $(\mathrm{T})$ or vehicle for the subsequent 30 hours as indicated. Luciferase (LUC) activities of the cell extracts were adjusted to transfection efficiencies according to $\beta$-galactosidase activities. The activity were obtained in COS-1 cells (not shown). These results argue against the possibility that the Pim-1 kinase activity-dependent repression of $A R$ function involves phosphorylation of AR at serines 213 and 791.

\section{Effect of Pim-1 on AR Activation Functions and DNA Binding}

To identify the AR domain(s) targeted by Pim-1, we studied Pim-1-mediated repression with a panel of rat AR deletion mutants. In agreement with our previous report (Ikonen et al, 1997), the activity of rAR $\Delta 641$ 902, with the entire LBD deleted, was independent of androgen and similar to that of wild-type rAR in the presence of androgen (Fig. 3). Upon coexpression of Pim-1, transactivation by rAR $\Delta 641-902$ was attenuated to a degree comparable to that of wild-type rAR, whereas Pim-1(K67M) had no major effect. Further truncation of the hinge region $(\Delta 619-902)$ resulted in a higher receptor activity, but this receptor form was also repressed by Pim-1, indicating that the AR LBD or hinge region are not required for the attenuation to occur. Deletion of the amino acids $212-295$ or 256295, encompassing the rAR AF1 core domain (Ikonen et al, 1997; Palvimo et al, 1993), significantly reduced the transcriptional activity of the receptor. However, the low activity of the mutants was still repressed by coexpressed Pim-1. Furthermore, coexpression of a steroid receptor coactivator, GRIP1, that interacts with both the AF1 and LBD of AR (Alen et al, 1999; Thompson et al, 2001) did not rescue the repressive effect of Pim-1 on AR (not shown). These results suggest that the Pim-1-mediated repression of $A R$ does not involve direct interaction of the kinase with the LBD or the AF1 of AR. We also performed coimmunoprecipitation experiments in COS-1 cells transfected with FLAG epitope-tagged Pim-1 and AR. Cell extracts were immunoprecipitated with anti-FLAG antibody, and the precipitated proteins were immunoblotted with anti-AR antibody. These experiments revealed no evidence for a direct Pim-1-AR interaction (not shown).

of AR without Pim-1 or Pim-1(K67M) in the presence of $100 \mathrm{~nm}$ T is set as 100 . The mean \pm SD values from two independent experiments performed in triplicates are shown. B (upper left panel), Immunoblot analysis of AR protein in PC-3 cells cotransfected with $100 \mathrm{ng}$ of Pim-1 or Pim-1(K67M). Protein samples from reporter gene assay lysates (pooled from triplicate wells) were separated on a $12 \%$ SDS-PAGE gel and immunoblotted with the anti-AR K333 antibody. Pim-1 and Pim-1(K67M) expression of the same samples was confirmed by reprobing the membrane with the anti-Pim-1 $19 \mathrm{FF}$ antibody (Iower left panel). B (right panel), Immunoblot analysis of endogenous Pim-1 in PC-3, LNCaP, and COS-1 cells. Protein samples from whole cell lysates were separated on a $12 \%$ SDS-PAGE gel (100 $\mu$ g protein/lane) and immunoblotted with the anti-Pim-1 19F7 antibody. The arrowheads depict the positions of endogenously expressed Pim-1. All immunoblottings were repeated twice with essentially identical results. C, Essentially the same experiment as in A, except that COS-1 cells were transfected with $2 \mathrm{ng}$ of AR expression vector and HeLa cells were transfected with $10 \mathrm{ng}$ of $A R$ vector. $D$, The same experiment as in A, except that LNCaP cells replaced PC-3 cells and pSG5-hAR was replaced by empty pSG5 vector. E, The same experiment as in A, except that PC-3 cells were transfected with the expression vectors encoding full-length wild-type $A R$ or AR mutant pSG5-hAR T877A. 
A

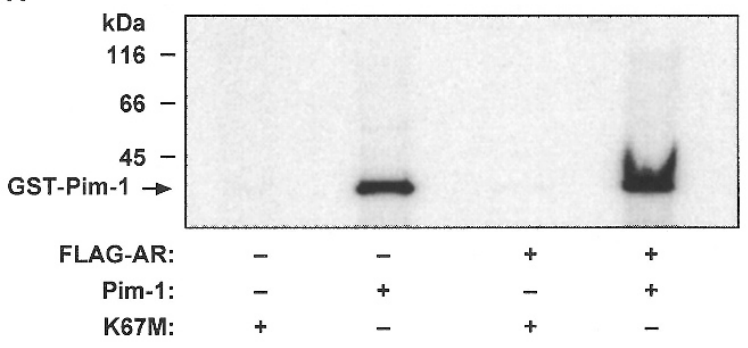

B

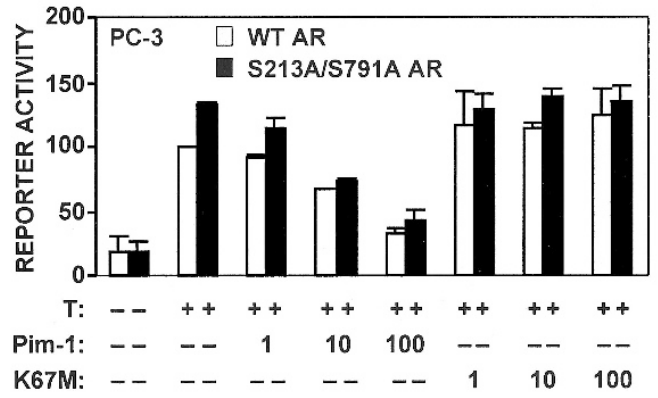

C

\begin{tabular}{|c|c|c|c|c|c|c|c|c|}
\hline kDa & & & & & & & & \\
\hline 119 & 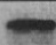 & 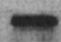 & $\longrightarrow$ & $=$ & $=$ & $\infty$ & $\rightarrow$ & $=$ \\
\hline $\mathrm{T}$ : & - & + & + & + & - & + & + & + \\
\hline NT AR: & + & + & + & + & - & - & - & - \\
\hline DM AR: & - & - & - & - & + & + & + & + \\
\hline Pim-1: & - & - & 100 & - & - & - & 100 & - \\
\hline K67M: & - & - & - & 100 & - & - & - & 100 \\
\hline
\end{tabular}

Figure 2.

In vitro phosphorylation analysis of AR by Pim-1. A, AR was immunopurified from COS-1 cells transfected with pcDNA-FLAG-hAR using a monoclonal anti-FLAG antibody and subjected to in vitro phosphorylation assays with glutathione-S-transferase (GST)-Pim-1 or GST-Pim-1(K67M). Empty pcDNAFLAG was transfected for preparation of control immunoprecipitates (- lanes). An arrow depicts the autophosphorylated GST-Pim-1. B, The influence of the AR mutations S213A and S791A on Pim-1-mediated repression. PC-3 cells were transfected with the expression vectors encoding wild-type (WT) human AR (open bars) or AR S213A/S791A (closed bars) expression vectors $(20 \mathrm{ng}$ ) along with $\mathrm{pPB}(-285 /+32)$-LUC $(200 \mathrm{ng}), \mathrm{pCMV} \beta(50 \mathrm{ng})$, and indicated amounts (ng) of Pim-1 or Pim-1(K67M). Twenty-four hours after transfection, the cells received fresh medium containing either $100 \mathrm{~nm} T$ or vehicle as indicated for the subsequent 30 hours. The activity of wild-type AR without Pim-1 or Pim-1(K67M) in the presence of $100 \mathrm{~nm}$ T is set as 100 . The mean \pm SD values from two independent experiments performed in triplicates are shown. C, Immunoblot analysis of WT AR or double mutant (DM) AR S213A/S791A coexpressed with either Pim-1 (100 ng) or Pim-1(K67M) (100 ng). Protein samples were pooled from triplicate wells of reporter gene assays and immunoblotted with the anti-AR K333 antibody. The experiment was repeated twice with essentially identical results.

We next investigated whether the apparent repression of AR activity by Pim-1 was a result of impaired DNA-binding activity of AR. AR was coexpressed in COS-1 cells with increasing amounts of Pim-1 or Pim-1(K67M), and whole cell extracts were analyzed by electrophoretic mobility shift assay. In agreement with our previous results (Thompson et al, 2001), only minimal binding of AR to DNA was detectable in the absence of androgen in the culture medium, whereas extracts derived from cells grown in the presence of testosterone displayed strong AR-DNA complex formation (Fig. 4). However, the DNA-binding activity of $A R$ was not influenced by the presence of either Pim-1 or Pim-1(K67M).

\section{Influence of Pim-1 on Other Steroid Receptors}

We further examined whether the repression by Pim-1 was specific for AR, or a more general phenomenon, by comparing transcriptional activities of glucocorticoid receptor (GR) and progesterone receptor (PR) in the presence and absence of ectopically expressed Pim-1 or Pim-1(K67M). As shown in Figure 5A, the activity of GR was attenuated by coexpressed Pim-1, although the kinase was less repressive than with AR. Interestingly, overexpression of Pim-1 did not markedly influence the activity of PR (Fig. 5A). Comparable results were seen in COS-1 cells (not shown). We also tested the effect of Pim-1 on estrogen receptor $\alpha$ $(\mathrm{ER} \alpha)$ using the $\mathrm{ERE}_{2}$ TATA-LUC reporter in PC-3 cells. Again, the activity of $\mathrm{ER} \alpha$ was inhibited by wild-type Pim-1 but not by the kinase-deficient Pim-1 mutant (Fig. 5B). Collectively, these data suggest that Pim-1 interferes with transcriptional mechanism(s) shared by many steroid receptors.

\section{Discussion}

The growth and maintenance of normal prostate is dependent on androgen stimulation. Disturbances in the androgen-signaling pathway may contribute to the development of CaP. Androgen ablation therapy usually achieves significant clinical responses during the early stages of the disease. Unfortunately, under the selective pressure of androgen withdrawal, androgendependent $\mathrm{CaP}$ can progress to an androgenindependent stage. The mechanism for the change in hormone dependency is not understood, and the change results almost invariably in a more aggressive and untreatable form of the disease (Arnold and Isaacs, 2002).

To improve CaP therapy, it is necessary to identify the critical molecular differences between benign and malignant prostate cells. Dhanasekaran et al (2001) screened benign prostatic hyperplasia, local $\mathrm{CaP}$, and metastatic, hormone-refractory $\mathrm{CaP}$ specimens for expression of genes that may distinguish $\mathrm{CaP}$. They showed that there is no or only weak expression of Pim-1 in most benign prostate samples, whereas about half of the metastatic CaP samples showed moderate to strong expression. Surprisingly little is known about the function of Pim-1. Recent studies have provided evidence that Pim-1 is involved in the pathogenesis of lymphoid or myeloid malignancies by promoting cell proliferation and/or survival (Amson et al, 1989; Lilly et al, 1999; Möröy et al, 1993; Nosaka et al, 1999; Shirogane et al, 1999).

In this work, we have investigated the potential of Pim-1 to influence AR function in CaP and other mammalian cell lines. Our data demonstrate that ectopic expression of Pim-1 has a cell type-dependent effect on AR. In PC-3 cells, a prostate cell line lacking 


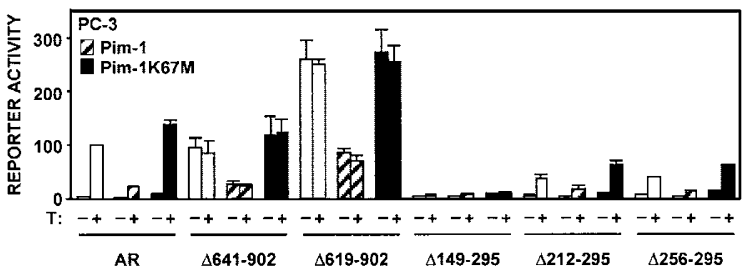

Figure 3.

Effect of Pim-1 on AR deletion mutants. The amino acids deleted from rat AR are shown for each mutant, with the numbers depicting the first and last residues deleted. Functional activities of the wild-type and mutant AR proteins in the absence (open bars) or presence of coexpressed Pim-1 (hatched bars) or Pim-1(K67M) (closed bars) were tested by cotransfecting the receptor expression vector $(20 \mathrm{ng})$ with pARE $\mathrm{E}_{4} \mathrm{tk}-\mathrm{LUC}(200 \mathrm{ng}), \operatorname{pCMV} \beta(50 \mathrm{ng})$, and either $25 \mathrm{ng}$ of Pim-1 or Pim-1(K67M) into PC-3 cells. All transfections contained equal amounts of DNA. Twenty-four hours after transfection, the cells received fresh medium containing either $100 \mathrm{~nm}$ T or vehicle as indicated for the subsequent 30 hours. The activity of wild-type AR without Pim-1 or Pim-1 (K67M) in the presence of $100 \mathrm{~nm} T$ is set as 100 . The mean \pm SD values from two independent experiments performed as triplicates are shown.

endogenous AR, Pim-1 down-regulated the function of ectopically expressed AR in a dose-dependent fashion. This phenomenon was also observed in COS-1 and HeLa cells. In contrast, Pim-1 did not attenuate AR function in LNCaP cells, a cell line that contains endogenous AR with the T877A point mutation. However, the function of the AR mutant T877A was repressed by $\mathrm{Pim}-1$ when expressed in $\mathrm{PC}-3$ and

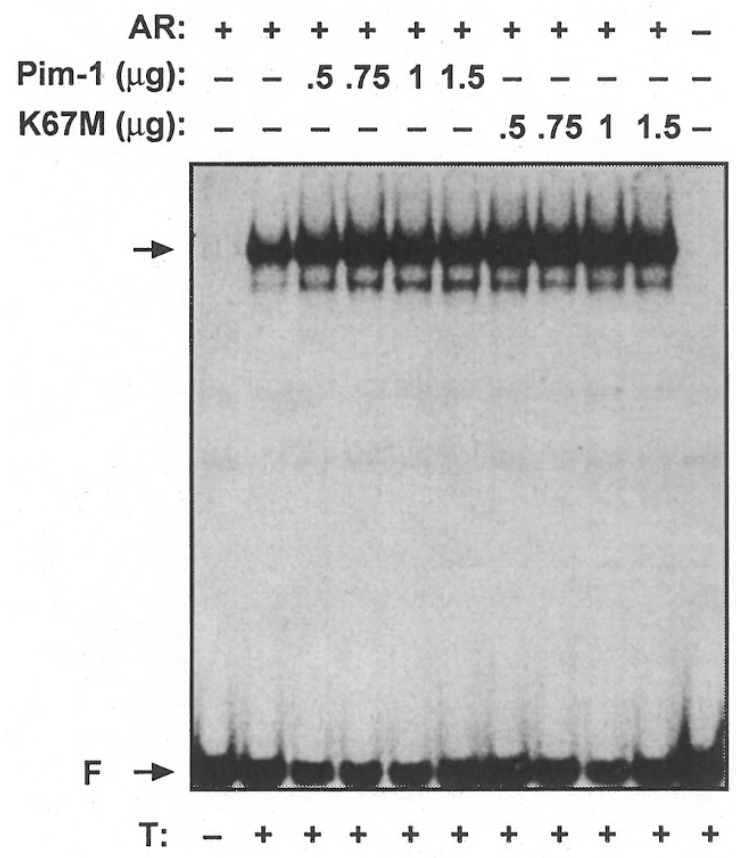

Figure 4.

Influence of Pim-1 on AR DNA binding. Equal amounts of whole cell extracts (10 $\mu \mathrm{g}$ protein) from COS-1 cells transfected on 6-well dishes with $0.5 \mu \mathrm{g}$ of AR and indicated amounts of Pim-1 or Pim-1(K67M) in the presence of $100 \mathrm{~nm}$ testosterone $(+T)$ or vehicle $(-T)$ were incubated for 60 minutes with ${ }^{32} \mathrm{P}$-labeled C3(1)-ARE at $22^{\circ} \mathrm{C}$. Protein-DNA complexes were resolved on a $4 \%$ nondenaturing polyacrylamide gel and detected by autoradiography. An arrowhead depicts the positions of specific androgen receptor-androgen response element (AR-ARE) complexes and $F$ refers to free probe. The experiment was repeated twice with essentially identical results.
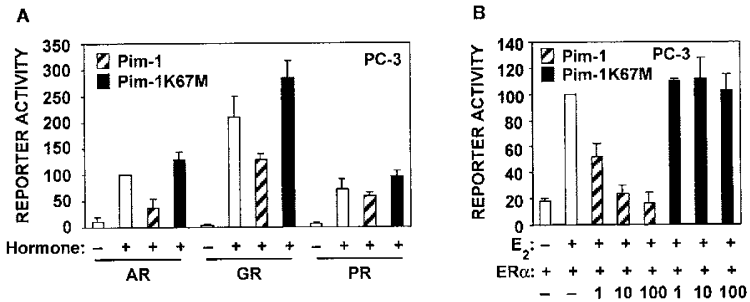

Figure 5.

Influence of Pim-1 on other steroid receptors. A, PC-3 cells were transfected with the expression vectors encoding either AR (20 ng), glucocorticoid receptor (GR) $(20 \mathrm{ng})$, or progesterone receptor (PR) $(20 \mathrm{ng})$ along with pARE $_{4}$ tk-LUC $(200 \mathrm{ng})$ and pCMV $\beta(50 \mathrm{ng})$ and coexpressed with either empty pcDNA3 vector (open bars), $25 \mathrm{ng}$ of Pim-1 (hatched bars), or $25 \mathrm{ng}$ of Pim-1(K67M) (closed bars). All transfections contained equal amounts of DNA. Twenty-four hours after transfection, the cells received fresh medium containing either $100 \mathrm{~nm}$ of respective hormone (dexamethasone for GR and progesterone for PR) or vehicle as indicated for the subsequent 30 hours. LUC activities of the cell extracts were adjusted according to $\beta$-galactosidase activities. The activity of wild-type AR without Pim-1 in the presence of $100 \mathrm{~nm}$ $T$ is set as 100 . The mean \pm SD values from two independent experiments performed in triplicates are shown. B, PC-3 cells were transfected with the expression vectors encoding wild-type human estrogen receptor $\alpha$ (pSG5$\mathrm{ER} \alpha)(20 \mathrm{ng})$ along with pERE 2 TATA-LUC $(200 \mathrm{ng}), \mathrm{pCMV} \beta(50 \mathrm{ng})$ and either empty vector (open bars) or indicated amounts (ng) of Pim-1 (hatched bars) or Pim-1(K67M) (closed bars). Twenty-four hours after transfection, the cells received fresh medium containing either $100 \mathrm{~nm}$ estradiol $\left(E_{2}\right)$ or vehicle as indicated for the subsequent 30 hours. The activity of $\mathrm{ER} \alpha$ without Pim-1 or Pim-1(K67M) in the presence of $100 \mathrm{~nm}_{2}$ is set as 100 . The mean \pm sD values from two independent experiments are shown.

COS-1 cells, indicating that the point mutation per se does not explain the lack of Pim-1-mediated attenuation of AR function in LNCaP cells. Because we observed that both PC-3 and LNCaP cells express only very low amounts of endogenous Pim-1 protein, the distinct responses of these CaP cells to ectopically expressed Pim-1 are likely to derive from other factors in their cellular context.

The repressive effects of Pim-1 on AR activity in PC-3, HeLa, and COS-1 cells were strictly dependent on its kinase activity, because the kinase-deficient Pim-1(K67M) mutant had minimal stimulatory or no effect on AR-dependent transcription. Pim-1 proteins can oligomerize with each other (Rainio et al, 2002), and the Pim-1 mutant may therefore compete with the endogenous Pim-1 by sequestering it into inactive complexes. The phosphorylation consensus site of Pim-1 (Friedmann et al, 1992) resembles that of another Ser/Thr kinase, Akt/PKB (Alessi et al, 1996), which has also been implicated in the regulation of $A R$ function (Lin et al, 2001). It was proposed that Akt/ PKB phosphorylates AR at serine residues 213 and 791 and thereby causes attenuation of receptor activity. However, contradicting results also exist, in that Akt/PKB has also been shown to activate AR function (Manin et al, 2002; Wen et al, 2000). We mutated both the postulated Akt/PKB phosphorylation sites of AR to alanines, but the double mutant still responded to Pim-1 in a fashion comparable to wild-type AR, arguing against the serine residues 213 and 791 being involved in the repression of AR function by Pim-1. Moreover, AR was not phosphorylated by the kinase in vitro. 
In our search for other molecular mechanisms underlying Pim-1-mediated attenuation of AR activity, we ruled out simple explanations such as altered receptor expression or DNA binding. Moreover, no direct interaction between Pim-1 and AR was seen in coimmunoprecipitation experiments, and ectopic expression of Pim-1 did not alter the subcellular localization of AR (not shown). The finding that LBDdeleted AR was also repressed by Pim-1 indicates that the hormone-binding function of $A R$ is not involved. Neither was the intact AR AF1 needed for repression by $\mathrm{Pim}-1$. Pim-1 was also capable of attenuating GR- and ER $\alpha$-dependent transcription, suggesting that it regulates a component shared by many steroid receptors in transcriptional regulation.

Collectively, our data suggest that Pim-1 abrogates AR function via an indirect mechanism, probably by phosphorylating some protein(s) involved in transcriptional control or regulation of chromatin. Pim-1 has recently been demonstrated to interact with proteins such as heterochromatin protein 1 (Koike et al, 2000) and the transcriptional coactivator p100 (Leverson et al, 1998). Although heterochromatin protein 1 is part of a larger protein complex suggested to be stabilized by Pim-1 during mitosis (Bhattacharya et al, 2002), p100 has been shown to cooperate with Pim-1 to enhance the activity of the c-Myb transcription factor (Leverson et al, 1998). Pim-1 can also stimulate activities of other transcription factors such as NFATc1 (Rainio et al, 2002), possibly by facilitating recruitment of additional coactivators. The cell context-dependent repression of AR function by Pim-1 in CaP cell lines, together with the observation that this kinase is overexpressed in about one-half of $\mathrm{CaP}$ specimens, indicates that Pim-1 may contribute to the function of AR during the progression of $\mathrm{CaP}$. Our inability to detect Pim-1 protein in metastasis-derived LNCaP cells is in line with decreased expression of the Pim-1 gene in CaPs being associated with poor prognosis (Dhanasekaran et al, 2001). In view of this, Pim-1 may be one of the determinants governing the transition of CaP from an androgen-dependent to an androgen-independent state. However, to better understand the role of Pim-1 in this context, cell models (with identical genetic backgrounds) mimicking the situation before and after transformation to the androgen-independent state need to be developed. Likewise, the physiologic substrates of this kinase should be identified and mechanisms controlling its catalytic activity clarified.

\section{Materials and Methods}

\section{Plasmids}

Plasmids encoding full-length human AR, pSG5-hAR and pCMV-hAR, have been described (Adeyemo et al, 1993; Simental et al, 1991). pSG5-hER $\alpha$ and pSG5hPR1 encoding human ER $\alpha$ and human PR1 were gifts from Benita Katzenellenbogen (University of Illinois) and Pierre Chambon (INSERM, Illkirch, France), respectively. pSG5-hGR that encodes full-length human GR has been described (Moilanen et al, 1998). AR mutant T877A (Veldscholte et al, 1990) was incorporated into pSG5-hAR using PCR techniques. pSG5hAR S213A/S791A was created by combining the single AR point mutations S213A (Wen et al, 2000) and S791A (Wen et al, 2000) by digesting pSG5-hAR S213A with $\mathrm{Kpnl}$ and $\mathrm{BamH1}$ and ligating back a corresponding restriction fragment from pSG5-hAR S791A. Overlap PCR was used to create the mutant S213A, and PCR fragments were digested with AfIII and Eco47III and ligated into a corresponding restriction site in pSG5-hAR. The mutants S791A and T877A were created using the QuickChange Site-Directed Mutagenesis Kit (Stratagene, La Jolla, California). The primer sequences are available upon request. Mutation incorporation was confirmed by sequencing both strands using the Pharmacia ALFexpress DNA sequencing system (Amersham Biosciences, Buckinghamshire, United Kingdom). pcDNA-FLAG-hAR (Poukka et al, 2000), pcDNA3-Pim-1, pcDNA3-Pim1(K67M) (a kinase-inactive mutant), pCMV-Pim-1FLAG, pGEX-2T-Pim-1, and pGEX-2T-Pim-1(K67M) have been described (Leverson et al, 1998; Rainio et al, 2002). pPB $(-285 /+32)$-LUC containing nucleotides -285 to +32 of the rat probasin promoter driving the firefly LUC coding region; $p A R E_{2} t k-L U C$ and $\mathrm{pARE}_{4}$ tk-LUC containing two or four androgen response elements, respectively, inserted before thymidine kinase promoter; and $p E_{2} E_{2}$ TATA-LUC containing two estrogen response elements in front of minimal TATA sequence have been described (Aarnisalo et al, 1998; Karvonen et al, 1997; Moilanen et al, 1998; Palvimo et al, 1996). $\operatorname{pCMV} \beta$ ( $\beta$-galactosidase expression vector) used as an internal control for transfection efficiency was from BD Biosciences Clontech (Palo Alto, California).

\section{Cell Culture and Transfections}

PC-3 cells [from American Type Culture Collection (ATCC), Manassas, ATCC, Virginia] were maintained in Nutrient Mixture F-12 (HAM) containing penicillin (25 $\mathrm{U} / \mathrm{ml})$, streptomycin $(25 \mathrm{U} / \mathrm{ml})$, and $7 \%$ fetal bovine serum and supplemented with L-glutamine ( $250 \mathrm{mg} / \mathrm{L})$. Transfections were performed using FuGENE 6 reagent (Roche Molecular Biochemicals, Mannheim, Germany) according to the manufacturer's instructions. In brief, $60 \times 10^{3} \mathrm{PC}-3$ cells were seeded on 12-well plates 48 hours before transfection. Two hundred nanograms of reporter plasmid, $50 \mathrm{ng}$ of $\mathrm{pCMV} \beta$, $20 \mathrm{ng}$ of AR, and indicated amounts of Pim-1 expression constructs were transfected. Twenty-four hours after transfection, the cells received fresh medium containing $7 \%$ charcoal-stripped fetal bovine serum and $100 \mathrm{~nm}$ testosterone (T) or vehicle as indicated. After a 30-hour culture, the cells were harvested, lysed in reporter lysis buffer (Promega, Madison, Wiscon$\sin )$, and the LUC and $\beta$-galactosidase activities were assayed as described (Ikonen et al, 1997). LNCaP cells (from ATCC) were plated 48 hours before transfection at a density of $65 \times 10^{3}$ cells/well on 12 -well plates. Throughout the experiment the cells were maintained in RPMI 1640 medium containing penicillin 
(25 U/ml), streptomycin $(25 \mathrm{U} / \mathrm{ml})$, and $10 \%$ fetal bovine serum and supplemented with L-glutamine (2 $\mathrm{mm})$. Twenty-four hours after transfection, the medium was supplemented with either $100 \mathrm{~nm}$ T or vehicle as indicated. After a 30-hour culture, the cells were harvested, lysed in reporter lysis buffer, and LUC and $\beta$-galactosidase activities were measured. COS-1 cells (ATCC) were maintained and transfected with $200 \mathrm{ng}$ of reporter plasmid, $50 \mathrm{ng}$ of $\mathrm{pCMV} \beta, 2 \mathrm{ng}$ of $\mathrm{AR}$, and indicated amounts of Pim-1 expression constructs as described (Thompson et al, 2001). HeLa cells (ATCC) were maintained and transfected with $200 \mathrm{ng}$ of reporter plasmid, $50 \mathrm{ng}$ of $\mathrm{pCMV} \beta, 10 \mathrm{ng}$ of $\mathrm{AR}$, and indicated amounts of Pim-1 expression constructs as described (Poukka et al, 2000).

\section{Immunoblot Analysis, Electrophoretic Mobility Shift Assay, Coimmunoprecipitation, and In Vitro Phosphorylation Assay}

Immunoblotting, preparation of whole cell extracts, and electrophoretic mobility shift assay were performed as previously described (Thompson et al, 2001) from cells expressing pCMV-hAR, pcDNA3Pim-1, and pcDNA3-Pim-1(K67M). Coimmunoprecipitation assay with FLAG-tagged Pim-1 was performed essentially as described (Kotaja et al, 2002). Briefly, COS-1 cells were collected in PBS, and cell extracts were prepared in radioimmunoprecipitation assay 2 buffer [50 nм Tris- $\mathrm{HCl}(\mathrm{pH} 7.8), 150 \mathrm{~nm} \mathrm{NaCl,} 5$ mм EDTA, $15 \mathrm{~mm} \mathrm{MgCl}_{2}$, 0.5\% Nonidet P-40, 0.3\% Triton $\mathrm{X}-100,1 \mathrm{~mm}$ dithiothreitol, 1:200-diluted protease inhibitor cocktail, and $10 \mathrm{~mm} \mathrm{~N}$-ethylmaleimide]. Immunoprecipitation with a mouse M2 anti-FLAG mAb (Sigma-Aldrich) was performed as previously described (Moilanen et al, 1998). Bound proteins were released in concentrated SDS sample buffer, resolved by SDS-PAGE, and immunoblotted as described (Thompson et al, 2001), using antibodies specific for AR (Karvonen et al, 1997) or Pim-1 (19F7; Santa Cruz). In vitro phosphorylation assays were performed essentially as described (Rainio et al, 2002). Briefly, FLAG-tagged proteins were expressed in COS-1 cells $\left(10^{6}\right)$ that were seeded on $10-\mathrm{cm}$ plates 24 hours before transfection. Five micrograms of FLAG-hAR or empty FLAG vector were transfected using the FuGENE 6 reagent according to the manufacturer's instructions. Twenty-four hours after transfection, the cells received fresh DMEM containing penicillin (25 $\mathrm{U} / \mathrm{ml})$, streptomycin $(25 \mathrm{U} / \mathrm{ml})$, and $10 \%$ fetal bovine serum. Cells were cultured for a further 30 hours before being collected in PBS and then lysed in radioimmunoprecipitation assay 2 buffer. Aliquots $(250 \mu \mathrm{g})$ of proteins were immunoprecipitated as described above and washed three times with PBS to remove detergents. The immunoprecipitates were then subjected to in vitro kinase assays with bacterially expressed wild-type or the K67M mutant of GSTPim-1 fusion protein (Rainio et al, 2002). Equal expression levels of GST fusion proteins were confirmed by Coomassie staining after gel electrophoresis and those of immunoprecipitates by immunoblotting of parallel samples. Confirmation of FLAG-hAR expression was performed by immunoblotting the cell lysates with an anti-FLAG M2 antibody.

\section{Acknowledgements}

The excellent technical assistance of Ms. Leena Pietilä, Ms. Katja Kiviniemi, Ms. Salla Ranta, Ms. Seija Mäki, and Ms. Kaija-Liisa Laine is gratefully acknowledged.

\section{References}

Aarnisalo P, Palvimo JJ, and Jänne OA (1998). CREB-binding protein in androgen receptor-mediated signaling. Proc Natl Acad Sci USA 95:2122-2127.

Abate-Shen C and Shen MM (2000). Molecular genetics of prostate cancer. Genes Dev 14:2410-2434.

Adeyemo O, Kallio PJ, Palvimo JJ, Kontula K, and Jänne OA (1993). A single-base substitution in exon 6 of the androgen receptor gene causing complete androgen insensitivity: The mutated receptor fails to transactivate but binds DNA in vitro. Hum Mol Genet 2:1809-1812.

Alen P, Claessens F, Verhoeven G, Rombauts W, and Peeters B (1999). The androgen receptor amino-terminal domain plays a key role in $\mathrm{p} 160$ coactivator-stimulated gene transcription. Mol Cell Biol 19:6085-6097.

Alessi DR, Caudwell FB, Andjelkovic M, Hemmings BA, and Cohen $P$ (1996). Molecular basis for the substrate specificity of protein kinase B: Comparison with MAPKAP kinase-1 and p70 S6 kinase. FEBS Lett 399:333-338.

Amson R, Sigaux F, Przedborski S, Flandrin G, Givol D, and Telerman A (1989). The human protooncogene product p33pim is expressed during fetal hematopoiesis and in diverse leukemias. Proc Natl Acad Sci USA 86:8857-8861.

Arnold JT and Isaacs JT (2002). Mechanisms involved in the progression of androgen-independent prostate cancers: It is not only the cancer cell's fault. Endocr Relat Cancer 9:61-73.

Beato M, Herrlich P, and Schütz G (1995). Steroid hormone receptors: Many actors in search of a plot. Cell 83:851-857.

Bhattacharya N, Wang Z, Davitt C, McKenzie IF, Xing PX, and Magnuson NS (2002). Pim-1 associates with protein complexes necessary for mitosis. Chromosoma 111:80-95.

Buckley AR, Buckley DJ, Leff MA, Hoover DS, and Magnuson NS (1995). Rapid induction of pim-1 expression by prolactin and interleukin-2 in rat $\mathrm{Nb} 2$ lymphoma cells. Endocrinology 136:5252-5259.

Craft N, Shostak Y, Carey M, and Sawyers CL (1999). A mechanism for hormone-independent prostate cancer through modulation of androgen receptor signaling by the HER-2/neu tyrosine kinase. Nat Med 5:280-285.

Cuypers HT, Selten G, Quint W, Zijlstra M, Maandag ER, Boelens W, van Wezenbeek P, Melief C, and Berns A (1984). Murine leukemia virus-induced T-cell lymphomagenesis: Integration of proviruses in a distinct chromosomal region. Cell 37:141-150.

Dautry F, Weil D, Yu J, and Dautry-Varsat A (1988). Regulation of pim and myb mRNA accumulation by interleukin 2 and interleukin 3 in murine hematopoietic cell lines. J Biol Chem 263:17615-17620. 
Dhanasekaran SM, Barrette TR, Ghosh D, Shah R, Varambally S, Kurachi K, Pienta KJ, Rubin MA, and Chinnaiyan AM (2001). Delineation of prognostic biomarkers in prostate cancer. Nature 412:822-826.

Domen J, van der Lugt N, Laird PW, Saris CJ, and Berns A (1993). Analysis of Pim-1 function in mutant mice. Leukemia Suppl 2:S108-S112.

Eichmann A, Yuan L, Bréant C, Alitalo K, and Koskinen PJ (2000). Developmental expression of Pim kinases suggests functions also outside of the hematopoietic system. Oncogene 19:1215-1224.

Friedmann M, Nissen MS, Hoover DS, Reeves R, and Magnuson NS (1992). Characterization of the proto-oncogene pim-1: Kinase activity and substrate recognition sequence. Arch Biochem Biophys 298:594-601.

Gelmann EP (2002). Molecular biology of the androgen receptor. J Clin Oncol 20:3001-3015.

He B, Kemppainen JA, and Wilson EM (2000). FXXLF and WXXLF sequences mediate the $\mathrm{NH}$-terminal interaction with the ligand binding domain of the androgen receptor. J Biol Chem 275:22986-22994.

Ikonen T, Palvimo JJ, and Jänne OA (1997). Interaction between the amino- and carboxyl-terminal regions of the rat androgen receptor modulates transcriptional activity and is influenced by nuclear receptor coactivators. J Biol Chem 272:29821-29828.

Karvonen U, Kallio PJ, Jänne OA, and Palvimo JJ (1997). Interaction of androgen receptors with androgen response element in intact cells: Roles of amino- and carboxyl-terminal regions and the ligand. J Biol Chem 272:15973-15979.

Koike $\mathrm{N}$, Maita $\mathrm{H}$, Taira $\mathrm{T}$, Ariga $\mathrm{H}$, and Iguchi-Ariga SM (2000). Identification of heterochromatin protein 1 (HP1) as a phosphorylation target by Pim-1 kinase and the effect of phosphorylation on the transcriptional repression function of HP1(1). FEBS Lett 467:17-21.

Kotaja N, Karvonen U, Jänne OA, and Palvimo JJ (2002). PIAS proteins modulate transcription factors by functioning as SUMO-1 ligases. Mol Cell Biol 22:5222-5234.

Leverson JD, Koskinen PJ, Orrico FC, Rainio EM, Jalkanen $\mathrm{KJ}$, Dash AB, Eisenman RN, and Ness SA (1998). Pim-1 kinase and $\mathrm{p} 100$ cooperate to enhance $\mathrm{c}-\mathrm{Myb}$ activity. Mol Cell 2:417-425.

Lilly M, Le T, Holland P, and Hendrickson SL (1992). Sustained expression of the pim-1 kinase is specifically induced in myeloid cells by cytokines whose receptors are structurally related. Oncogene 7:727-732.

Lilly M, Sandholm J, Cooper JJ, Koskinen PJ, and Kraft A (1999). The Pim-1 serine kinase prolongs survival and inhibits apoptosis-related mitochondrial dysfunction in part through a bcl-2-dependent pathway. Oncogene 18:4022-4031.

Lin HK, Yeh S, Kang HY, and Chang C (2001). Akt suppresses androgen-induced apoptosis by phosphorylating and inhibiting androgen receptor. Proc Natl Acad Sci USA 98:7200-7205.

Manin M, Baron S, Goossens K, Beaudoin C, Jean C, Veyssiere G, Verhoeven G, and Morel L (2002). Androgen receptor expression is regulated by the phosphoinositide 3-kinase/Akt pathway in normal and tumoral epithelial cells. Biochem J 366:729-736.
Mochizuki T, Kitanaka C, Noguchi K, Muramatsu T, Asai A and Kuchino $Y$ (1999). Physical and functional interactions between Pim-1 kinase and Cdc25A phosphatase. J Biol Chem 274:18659-18666.

Moilanen A, Rouleau N, Ikonen T, Palvimo JJ, and Jänne OA (1997). The presence of a transcription activation function in the hormone-binding domain of androgen receptor is revealed by studies in yeast cells. FEBS Lett 412:355-358.

Moilanen AM, Poukka H, Karvonen U, Häkli M, Jänne OA, and Palvimo JJ (1998). Identification of a novel RING finger protein as a coregulator in steroid receptor-mediated gene transcription. Mol Cell Biol 18:5128-5139.

Moras D and Gronemeyer H (1998). The nuclear receptor ligand-binding domain: Structure and function. Curr Opin Cell Biol 10:384-391.

Möröy T, Grzeschiczek A, Petzold S, and Hartmann KU (1993). Expression of a Pim-1 transgene accelerates lymphoproliferation and inhibits apoptosis in Ipr/lpr mice. Proc Natl Acad Sci USA 90:10734-10738.

Möröy T, Verbeek S, Ma A, Achaoso P, Berns A, and Alt F (1991). $\mathrm{E}_{\mu} \mathrm{N}$ - and $\mathrm{E} \mu \mathrm{L}-m y c$ cooperate with $\mathrm{E} \mu$ pim-1 to generate lymphoid tumors at high frequency in doubletransgenic mice. Oncogene 6:1941-1948.

Nosaka T, Kawashima T, Misawa K, Ikuta K, Mui ALF, and Kitamura T (1999). STAT5 as a molecular regulator of proliferation, differentiation and apoptosis in hematopoietic cells. EMBO J 18:4754-4765.

Palvimo JJ, Kallio PJ, Ikonen T, Mehto M, and Jänne OA (1993). Dominant negative regulation of trans-activation by the rat androgen receptor: Roles of the $\mathrm{N}$-terminal domain and heterodimer formation. Mol Endocrinol 7:1399-1407.

Palvimo JJ, Reinikainen P, Ikonen T, Kallio PJ, Moilanen A, and Jänne OA (1996). Mutual transcriptional interference between RelA and androgen receptor. J Biol Chem 271: 24151-24156.

Poukka H, Karvonen U, Jänne OA, and Palvimo JJ (2000). Covalent modification of the androgen receptor by small ubiquitin-like modifier 1 (SUMO-1). Proc Natl Acad Sci USA 97:14145-14150.

Quigley CA, De Bellis A, Marschke KB, el-Awady MK, Wilson EM, and French FS (1995). Androgen receptor defects: Historical, clinical, and molecular perspectives. Endocr Rev $16: 271-321$

Rainio EM, Sandholm J, and Koskinen PJ (2002). Cutting edge: Transcriptional activity of NFATc1 is enhanced by the Pim-1 kinase. J Immunol 168:1524-1527.

Shirogane T, Fukada T, Muller JMM, Shima DT, Hibi M, and Hirano T (1999). Synergistic roles for Pim-1 and c-Myc in STAT3-mediated cell cycle progression and antiapoptosis. Immunity 11:709-719.

Simental JA, Sar M, Lane MV, French FS, and Wilson EM (1991). Transcriptional activation and nuclear targeting signals of the human androgen receptor. J Biol Chem 266:510518.

Sorrentino V, McKinney MD, Giorgi M, Geremia R, and Fleissner $E$ (1988). Expression of cellular protooncogenes in the mouse male germ line: A distinctive 2.4-kilobase pim-1 transcript is expressed in haploid postmeiotic cells. Proc Natl Acad Sci USA 85:2191-2195. 
Thompson J, Saatcioglu F, Jänne OA, and Palvimo JJ (2001). Disrupted amino- and carboxyl-terminal interactions of the androgen receptor are linked to androgen insensitivity. Mol Endocrinol 15:923-935.

van Lohuizen M, Verbeek S, Krimpenfort P, Domen J, Saris C, Radaszkiewicz T, and Berns A (1989). Predisposition to lymphomagenesis in pim-1 transgenic mice: Cooperation with c-myc and $\mathrm{N}-m y c$ in murine leukemia virus-induced tumors. Cell 56:673-682.

Veldscholte J, Ris-Stalpers C, Kuiper GG, Jenster G, Berrevoets $\mathrm{C}$, Claassen $\mathrm{E}$, van Rooij $\mathrm{HC}$, Trapman J, Brinkmann AO, and Mulder E (1990). A mutation in the ligand binding domain of the androgen receptor of human LNCaP cells affects steroid binding characteristics and response to antiandrogens. Biochem Biophys Res Commun 173:534-540.
Wang Z, Bhattacharya N, Mixter PF, Wei W, Sedivy J, and Magnuson NS (2002). Phosphorylation of the cell cycle inhibitor $\mathrm{p} 21^{\mathrm{Cip} 1 / \mathrm{WAF} 1}$ by Pim-1 kinase. Biochim Biophys Acta 1593:45-55.

Wen Y, Hu MC, Makino K, Spohn B, Bartholomeusz G, Yan $\mathrm{DH}$, and Hung MC (2000). HER-2/neu promotes androgenindependent survival and growth of prostate cancer cells through the Akt pathway. Cancer Res 60:6841-6845. 